\title{
Soroprevalência e fatores de risco para a infecção pelo herpesvírus bovino tipo 1 (BHV-1) no Estado de Goiás, Brasil
}

\author{
Seroprevalence and risk factors to the infectious by bovine herpesvirus \\ type 1 (BHV-1) in Goiás State, Brazil
}

\section{Alessandra Cartafina Vaz da Costa Barbosa ${ }^{1}$ Wilia Marta Elsner Diederichsen de Brito ${ }^{2}$ Bernadete Tavares Alfaia ${ }^{3}$}

\section{RESUMO}

Este foi um estudo descritivo e transversal que objetivou estimar a soroprevalência de anticorpos contra o herpesvírus bovino tipo 1 (BHV-1) em animais não vacinados e determinar os potenciais fatores de risco para a infecção em rebanhos bovinos no Estado de Goiás, Brasil. Amostras sorológicas de 6.932 animais em 892 propriedades de 232 municípios em Goiás foram coletadas entre março e setembro/ 2002 e a pesquisa de anticorpos foi realizada através de teste de soroneutralização. Informações dos animais e propriedades amostradas foram registradas em questionários. Os dados obtidos foram analisados através do programa Epi Info versão 6.04. A soroprevalência para o BHV-1 nos animais foi de $51,9 \%$. Das 892 propriedades amostradas, $98,5 \%$ apresentaram, pelo menos, um animal soropositivo e todos os municípios pesquisados (100\%) apresentaram, pelo menos, uma propriedade positiva demonstrando que a infecção pelo $B H V-1$ encontra-se altamente disseminada entre rebanhos bovinos dos municípios de Goiás. Em relação aos fatores de risco, apenas a idade mostrou-se associada à soropositividade nos animais, enquanto nas propriedades, nenhuma das variáveis analisadas foi considerada como fator de risco. Este fato pode ser devido à elevada prevalência da infecção na região.

Palavras-chave: bovinos, herpesvírus bovino 1, soroneutralização, prevalência, fatores de risco.

\section{ABSTRACT}

The main objectives of this cross-sectional study were to estimate $B H V-1$ seroprevalence in a population of non-vaccinated cattle in Goiás State, Brazil, and to determine potential risk factors related to the seroprevalence. It was conducted from March to September, 2002. Serum samples were collected from 6,932 animals of 892 herds from 232 municipalities in Goiás. Sera were tested for antibodies against $B H V-1$ using the serum neutralization test. Information regarding animals and herds were recorded through a personal interview with the farmer or farmer manager. The data were analyzed using Epi Info 6.04 and Epi Info for Windows 3.01 programs. The seroprevalence was 51.9\%. Eight hundred and seventy nine out of 892 herds (98.5\%) had at least one seropositive animal, and all (100\%) municipalities showed at least one herd/animal positive. Only age influenced the distribution of neutralization antibodies to this virus in animals. None of the exposure variables analyzed was considered as risk factors for the infection with $\mathrm{BHV}-1$ in cattle herds. With these results we conclude that the infection is spread among cattle herds of municipalities in the state of Goiás.

Key words: bovines, bovine herpesvirus 1, serum neutralization, prevalence, risk factors.

\section{INTRODUÇÃO}

O herpesvírus bovino 1 (BHV-1) é um importante agente infeccioso que causa perdas significativas na pecuária bovina (HAGE et al., 1996). Como todos os herpesvírus, após infecção aguda, o BHV-1 permanece em estado de latência, alojando-se em gânglios nervosos regionais, podendo ser reativado quando os animais são expostos a fatores predisponentes estressantes que diminuem sua

\footnotetext{
${ }^{1}$ Agência Goiana de Desenvolvimento Rural e Fundiário, Goiânia, Goiás, Brasil.

${ }^{2}$ Setor de Microbiologia, Instituto de Patologia Tropical e Saúde Pública, Universidade Federal de Goiás, Goiânia, Goiás, Brasil.

${ }^{3}$ Instituto de Ciências Biológicas, Universidade Federal de Goiás, Goiânia, Goiás, Brasil.
} 
resistência imunológica e, com isso, ser excretado infectando outros animais susceptíveis no rebanho (JONES, 2003).

Segundo vários autores, o mais importante fator de risco para a infecção é a introdução no rebanho de animais em período de incubação, em fase aguda, ou latentemente infectados pelo vírus. Estas situações normalmente ocorrem em propriedades que têm como característica uma criação mais aberta à exposição, estando seus rebanhos sempre em contato com outros, quer seja por participação em eventos agropecuários ou através de utilização de pastagens em comum. Além disso, há autores que citam ainda o risco gerado por visitas técnicas e por contato com outras espécies que funcionariam como potenciais carreadores ou vetores do vírus de uma fazenda a outra e a alta densidade animal por área que levaria ao maior contato entre animais (WENTINK et al., 1993; VAN SCHAIK et al., 1998; VAN WUIJCKHUISE et al., 1998; VAN SCHAIK et al., 2002).

O BHV-1 tem distribuição mundial e sua prevalência em rebanhos bovinos atinge coeficientes variados em diferentes regiões (STRAUB, 2001). No Brasil, os coeficientes de soropositividade variam de 10,6\% a 96\% (LOVATTO et al., 1995; VIDOR et al., 1995; LAGE et al., 1996; TONIN et al., 1996; MELO et al., 1997; VIEIRA et al., 2003), porém, apesar da grande variação relatada, a maioria dos estudos foi realizada ou com número pequeno de amostras englobando poucos municípios ou, muitas vezes, com populações específicas ou ambas as situações. Em Goiás, existe uma carência de levantamentos epidemiológicos e os raros estudos realizados indicam altos coeficientes, mas que também não representam o Estado como um todo (ANUNCIAÇÃO et al., 1989; FARIA et al., 2003; VIEIRA et al., 2003). Outra questão a ressaltar é que, em nível de Brasil, há uma deficiência de pesquisas que abordem fatores de risco para esta infecção.

Os objetivos deste estudo foram estimar a soroprevalência da infecção pelo BHV-1 em animais não vacinados de rebanhos bovinos no Estado de Goiás, perfazendo um total de 232 municípios, 892 propriedades e 6932 amostras, e determinar potenciais fatores de risco associados à infecção.

\section{MATERIAL E MÉTODOS}

Amostragem e coleta de dados

A amostragem foi calculada inicialmente, pelo número de propriedades a participarem deste estudo e, em seguida, pelo número total de animais que poderiam estimar a prevalência da infecção pelo herpesvírus bovino 1 no Estado de Goiás.
O estudo foi realizado paralelamente ao Programa Nacional de Controle e Erradicação da Brucelose e Tuberculose Animal (PNCEBTA), seguindo, portanto, os padrões adotados no mesmo. Assim, o número de propriedades a serem amostradas seguiu os dados relativos à brucelose, bem como os questionários aplicados seguiram o modelo. A propriedade rural foi considerada a unidade primária de amostragem, ou seja, a unidade com um grupo de animais em contato suficiente para que todos tivessem o mesmo risco de serem infectados por um agente infeccioso introduzido no grupo. As propriedades selecionadas foram caracterizadas de acordo com sua atividade principal, na qual os animais estivessem submetidos às mesmas condições de manejo (ROCHA 2003).

As propriedades foram escolhidas aleatoriamente e o número de propriedades a participarem foi determinado segundo a fórmula da Organização Mundial da Saúde / Organização Panamericana da Saúde / Centro Panamericano de Zoonoses (1973). Admitiu-se um grau de confiança de 95\% e um erro máximo de 20\% da prevalência. Estimouse uma prevalência de $25 \%$.

Neste experimento, foram utilizadas 298 propriedades, correspondente ao número aproximado no estudo do PNCEBTA. Este valor foi estimado por estrato amostral, fazendo-se necessário multiplicá-lo ainda pelos três diferentes estratos de produção (corte, leite, misto), perfazendo um total de 894 propriedades. Duas propriedades foram retiradas da pesquisa por utilizarem vacinação contra BHV-1, condição interferente para prevalência desta infecção. O número total de animais a participarem do estudo foi determinado pela mesma fórmula utilizada para número de propriedades, no entanto, os índices estimados foram os apontados na literatura relativos à infecção ao BHV-1, sendo a prevalência para animais de 25\% (LOVATO et al. 1995, VIDOR et al. 1995), margem de erro de $4 \%$ e um intervalo de confiança de $95 \%$, obtendo-se um $n=7000$ amostras. Os animais foram estratificados em três faixas etárias, sendo que a composição de cada estrato foi feita através de seleção aleatória, utilizando-se a Tabela de Números Aleatórios. A porcentagem de animais dentro de cada faixa etária foi definida de acordo com os dados obtidos por MELO et al. (2002), que indicaram que a prevalência é maior em animais adultos do que em animais jovens. Com base nessa característica, foram coletadas aproximadamente 15\% para animais de 6 a 12 meses, 35\% para animais de 12 a 24 meses e de $50 \%$ para fêmeas acima de 24 meses. Desta forma, foram coletadas oito amostras por propriedade, porém, como algumas das propriedades 
sorteadas, por vezes, não tinham animais em uma das três faixas etárias preconizadas para o estudo, ou as amostras eram em quantidades insuficientes para o teste ou mesmo depois de testadas mostraram-se citotóxicas, foram retiradas 68 amostras, entrando na análise dos dados 6932.

Além dos soros coletados, foram preenchidos questionários contemplando dados das propriedades e do animal, dos quais foram retiradas as variáveis idade e ocorrência de aborto (referentes ao animal), região, tipo de exploração, tipo de criação, tipo de ordenha, uso de inseminação artificial, raça, presença de outros animais domésticos e/ou silvestres, compra e venda de reprodutores, aluguel de pasto, utilização de pasto em comum, utilização de piquete de parto, assistência veterinária, vacinação contra BHV-1 (referentes às propriedades) para a análise dos fatores de risco associados à infecção pelo BHV-1.

\section{Método sorológico}

Para detecção de anticorpos contra o BHV1, foi utilizada a técnica de soroneutralização (SN), conforme a OIE (2002) em duas diluições (1:2 e 1:4). O teste foi realizado em células de linhagem contínua de rim de bovino "Madin Darby Bovine Kidney" (MDBK, ATCC CCL-22), cultivadas em meio essencial mínimo (MEM; GIBCO BRL), suplementado com 6\% de soro fetal bovino (SFB; GIBCO BRL) e acrescido de gentamicina e anfotericina $\mathrm{B}$. Como antígeno, foi utilizada a amostra viral padrão Cooper do BHV-1 (ATCC-VR 864), com 100 TCID $_{50}$ por cavidade, titulado pelo método de Spearman-Karber (THRUSFIELD, 1999).

Com o objetivo de evitar resultados falsos, em todas as microplacas, foram feitos controles de célula, de vírus e de citotoxicidade dos soros. As amostras foram consideradas positivas para a presença de anticorpos, quando havia inibição de lise celular na diluição 1:4. As amostras que apresentaram citotoxicidade foram retiradas do estudo.
Processamento e análise dos dados

Os resultados obtidos foram analisados através do Programa Epi Info Versão 6.04 (DEAN et al., 1994) que determinou a freqüência das variáveis trabalhadas, as prevalências, os intervalos de confiança além de avaliar, por análise univariada, a associação entre possíveis fatores de risco e soropositividade à infecção. O teste estatístico utilizado foi o teste do qui quadrado $\left(\chi^{2}\right)$.

\section{RESULTADOS E DISCUSSÃO}

O presente trabalho foi um estudo descritivo e transversal em que, pela primeira vez, determinou-se a prevalência de forma mais ampla da infecção pelo BHV-1 em Goiás e uma análise dos possíveis fatores de risco associados a ela.

O número de animais amostrados de acordo com a faixa etária está descrito na tabela 1. A prevalência observada entre os animais, de 51,9\% (IC 95\% = 50,7 53,1), assemelha-se às observadas por MÉDICI et al. (2000) e CALDERON et al. (2003). Coeficientes menores ou maiores já foram descritos (LOVATO et al., 1995; VIDOR et al., 1995; TONIN et al., 1996; MELO et al., 1997), mas essas diferenças têm sido apontadas como sendo conseqüência do tipo de população bovina estudada, faixa etária, condições de manejo, técnicas de amostragem e de diagnóstico utilizadas, além das heterogeneidades regionais de cada estudo (LOVATO et al., 1995; STRAUB, 2001). Para o Estado de Goiás, onde a região, tipo de população e manejo são semelhantes ao desse estudo, os resultados são discrepantes (ANUNCIAÇÃO et al., 1989; FARIAet al., 2003; VIEIRAetal., 2003). Os resultados anteriores não podem ser considerados como reflexo da situação da infecção no Estado devido ao pequeno número de amostras analisadas ou por representarem grupos populacionais específicos.

Os resultados referentes à faixa etária (Tabela

1) são semelhantes e corroboram os resultados

Tabela 1 - Possível fator de risco para a infecção pelo BHV-1 pela análise univariada em bovinos, no Estado de Goiás, Brasil, 2002.

\begin{tabular}{|c|c|c|c|c|c|c|}
\hline \multirow{2}{*}{ Variáveis } & \multicolumn{4}{|c|}{ BHV-1 } & \multirow{2}{*}{$\mathrm{P}$} & \multirow{2}{*}{ Odds Ratio (IC*95\%) } \\
\hline & \multicolumn{2}{|c|}{ Positivos / Total } & \multicolumn{2}{|c|}{$\%$} & & \\
\hline \multicolumn{7}{|l|}{ Idade } \\
\hline $6-12$ & 213 & / & 861 & $(24,7)$ & $<0,001$ & $1,39 * *(1,16-1,67)$ \\
\hline $13-24$ & 794 & l & 2527 & $(31,4)$ & $<0,001$ & $5,92 * * *(5,28-6,64)$ \\
\hline$>24$ & 2589 & / & 3544 & $(73,1)$ & $<0,001$ & $8,25 * * * *(6,91-9,85)$ \\
\hline
\end{tabular}

*IC - Intervalo de confiança

** $\quad-$ OR entre $6-12$ e $13-24$ meses

*** - OR entre $13-24$ e $>24$ meses

**** - OR entre 6-12 e > 24 meses 
encontrados por SILVA et al. (1995) e MELO et al. (2002), que demonstraram que a idade é um fator de risco para a infecção, pois animais mais velhos têm mais oportunidades de exposição ao agente, em especial quando estes entram na fase reprodutiva.

Com relação à ocorrência de aborto, analisando animais acima de 24 meses ( $\mathrm{n}=3544)$, apenas $2,2 \%(n=77)$ sofreram aborto. A soropositividade em fêmeas que não abortaram (73,0\%) foi semelhante à de fêmeas que abortaram (76,6\%) indicando que o aborto não representa um fator de risco. Acredita-se que este resultado tenha sido em conseqüência a respostas involuntariamente equivocadas dadas neste item, pois o pequeno número de relatos de ocorrência de aborto (77) dentro de um grupo tão extenso de animais susceptíveis (3544), pode não condizer com a realidade do Estado.

As 892 propriedades analisadas, definidas pelo predomínio da exploração na área, leite, corte e mista, foram distribuídas de forma eqüitativa dentro das regiões estudadas, sendo leite (Sul e Sudeste) $31,7 \%$, corte (Norte e Nordeste) 28,5\% e mista (Sudoeste e Central) 39,8\%. Em relação ao tipo de criação, a maioria foi de criação extensiva $(91,8 \%)$ com menor índice entre criação semi-extensiva $(7,6 \%)$ e confinamento (0,6\%). Em $83,6 \%$ das propriedades, era realizada ordenha manual; em 3,9\% ordenha mecânica e nas restantes não era realizada ordenha. Quanto ao uso de inseminação artificial (IA), 89,3\% das propriedades não usavam; 8,6\% a utilizavam paralela à monta natural e 2,0\% utilizavam somente a IA. Na maioria das propriedades $(51,0 \%)$ eram criados animais mestiços, em $34,4 \%$ eram criados animais da raça zebu, em 9,8\% européia de leite, em 0,4\% européia de corte e em 4,4\% a criação de outras raças.

Quanto à presença de outros animais domésticos e silvestres, em $95,7 \%$ das propriedades foi relatada presença de eqüídeos, em 89,6\% cães; em $69,6 \%$ gatos; em $68,0 \%$ suínos; em $12,4 \%$ ovinos e caprinos e em $43,3 \%$ foi relatada a presença de animais silvestres.

A compra de reprodutores era realizada em $62,7 \%$ das propriedades, seja em exposições $(2,1 \%)$, leilões $(10,3 \%)$, de comerciantes $(14,1 \%)$ ou diretamente de fazendas (43,2\%). A venda de reprodutores foi citada em $37,7 \%$ das propriedades. Do total de propriedades, 61,8\% não alugavam ou usavam pasto alugado; 89,9\% não tinham pasto em comum com outra propriedade; $32,7 \%$ não utilizavam piquetes separados para fêmeas para fase de parto e/ ou pós-parto e $72,9 \%$ não recebiam assistência veterinária regularmente.
Das 892 propriedades incluídas no estudo, 98,5\% (IC 95\% = 97,5 - 99,2) apresentaram pelo menos um animal soropositivo, semelhantes ao observado em outros países (BOELART et al., 2000; CALDERÓN et al., 2003). Todos os 232 municípios analisados (100\%) apresentaram, pelo menos, uma propriedade positiva. Em relação ao Brasil, os coeficientes encontrados corroboram com RICHTZENHAIN et al. (1999) para vários Estados brasileiros e com VIEIRA et al. (2003) em Goiás confirmando que a infecção pelo BHV-1 encontra-se disseminada nos rebanhos do estado e do país.

A análise univariada demonstrou que nenhuma das variáveis analisadas apresentou-se como fator de risco para a infecção-pelo BHV-1 em propriedades, apesar de terem sido citadas como tal por diferentes autores (VAN WUIJCKHUISE et al., 1998; BOELAERT et al., 2000; VAN SCHAIK et al., 2001; VIEIRA et al., 2003).

Sobre o tipo de ordenha, apesar deste não ter sido considerado fator de risco para a infecção e nem ter sido citado na literatura como de risco, pode eventualmente sê-lo, já que a ordenha, manual ou mecânica, propicia o aglomeramento de animais e assim uma maior probabilidade de transmissão do vírus.

A monta natural poderia ser considerada como fator de risco, especialmente, quando se observa que a infecção de touros, em Goiás, é elevada (FARIA et al., 2003). A IA, se utilizada isolada e com cuidados, pode ser considerada um fator de proteção. A IA não mostrou ser um fator de risco neste estudo, o que concorda com VAN SCHAIK et al. (1998). A não associação aqui verificada pode ter ocorrido pelo fato de que a maioria das propriedades, independente de utilizar ou não a inseminação artificial, mostrou coeficientes elevados de positividade, demonstrando que tanto os touros quanto o sêmen utilizado na IA podem estar contaminados.

O contato de bovinos com algumas espécies animais, mesmo que eles não exerçam papel importante na disseminação do vírus, podem atuar como transmissores mecânicos quando se deslocam de um local a outro dentro e entre propriedades (VAN SCHAIK et al., 1998). A não associação como fator de risco pode não ter ocorrido, especialmente em relação aos animais silvestres, por estar este dado talvez subestimado, pois apenas 43,3\% dos questionários em relação a propriedades relataram a presença dos mesmos. A região estudada, entretanto, é reconhecida como de grande diversidade de fauna, sendo pouco provável não ocorrer o contato destes com o rebanho bovino. 
Veterinários, técnicos e tratadores podem ser capazes de transmitir o BHV-1 entre os animais através de fluidos nasais e genitais impregnados nas roupas ou mesmo pela lambedura de animais nestas (WENTINK et al., 1993). O uso de roupas exclusivas, fornecidas pela propriedade, pode minimizar o problema e ainda fazer com que um fator de risco reverta-se a um fator de proteção (VAN SCHAIK et al., 1998, 2001, 2002). Relacionado a isto, a variável "assistência veterinária” foi avaliada na análise dos riscos para o BHV-1, no entanto novamente não foi apontada como tal.

Resultado surpreendente foi o obtido na maior soropositividade observada em relação à utilização de piquetes separados para fêmeas nas fases de parto e/ou pós-parto, em comparação com àquelas que não separavam os animais. O esperado era que as primeiras, por si, fossem um fator de proteção para a infecção, já que os animais nesta fase estariam fisiologicamente imunodeprimidos podendo, assim, reativar e excretar o vírus se latentemente infectados. A separação, neste caso, impediria a disseminação para o restante do rebanho.

É importante enfatizar que a infecção pelo BHV-1 está extremamente disseminada no Estado de Goiás, conforme observado pelos coeficientes de prevalência apresentados em animais, propriedades e municípios. E, diferentemente de infecções que cursam de forma aguda, por ser um vírus de infecção latente, a soropositividade para o BHV-1 representa a presença do animal portador e potencial disseminador do vírus no rebanho por toda a vida.

Os resultados encontrados em relação a fatores de risco para propriedades geram dúvidas quanto ao seu real significado. Algumas das variáveis analisadas que deveriam portar-se como fatores de risco não foram mostradas como tal. Talvez isto se explique, porque parte da realidade das propriedades não condizia com a relatada nos questionários, inclusive pela incoerência de alguns números apresentados como resposta. Ou mesmo porque a infecção latente e, estando o vírus bastante disseminado em Goiás, pode ter impossibilitado assim, a discriminação de qualquer condição como fator de risco, visto que este risco já estava iminente.

Em conseqüência desta latência e desta alta prevalência, só se torna economicamente viável a implantação de programas de controle/erradicação, se esses forem baseados na prevenção de novas infecções combinada a remoção gradual de animais infectados e a utilização de vacinas marcadas (DIVAS), que permitem a diferenciação entre animal infectado e vacinado, além de melhoramento nas práticas de manejo do rebanho, como utilização de sêmen livre de BHV-1, reposição de animais livres da doença e quarentena (METTENLEITER, 1996; PITUCO et al., 1997; VAN WUIJCKHUISE et al., 1998).

\section{AGRADECIMENTOS}

Os autores agradecem à Agência Goiana de Desenvolvimento Rural e Fundiário (AGENCIARURAL) pela colaboração no desenvolvimento desse trabalho. Apoio financeiro: Conselho Nacional de Desenvolvimento Científico e Tecnológico - CNPq (proc. 521058/99-6)

\section{REFERÊNCIAS}

ANUNCIAÇÃO, A.V.M. et al. Presença de anticorpos para o herpesvírus bovino 1 (BHV-1) em bovinos nos Estados de Minas Gerais, Goiás e Rio de Janeiro através da prova de hemoaglutinação passiva. Arquivo Brasileiro de Medicina Veterinária e Zootecnia, v.41, n.5, p.433441, 1989.

BOELAERT, F. et al. Prevalence of bovine herpesvirus-1 in the Belgian cattle population. Preventive Veterinary Medicine, v.45, n.3-4, p.285-295, 2000.

CALDERON, S.J.J. et al. Seroprevalence of and risck factors for infectious bovine rhinotracheitis in beef cattle herds of Yucatan, México. Preventive Veterinary Medicine, v.57, p.199-208, 2003.

CENTRO PANAMERICANO DE ZOONOSES, Ramos Mejia. Procedimientos para estudios de prevalência de enfermidades crónicas en el ganado. Buenos Aires: CEPANZO, 1973. 33p (Nota Técnica 18)

DEAN, A. G. et al. Epi Info, Version 6: a word processing, data base and statistics program for epidemiology on microcomputers. Atlanta, Georgia, USA: Centers for Disease Control and Prevention, 1994.

FARIA, B.O. et al. Estudo de anticorpos contra o herpesvírus bovino tipo 1 em municípios de entorno de Goiânia, Go. Revista Brasileira de Reprodução Animal, v.27, n.3, p.543-545, 2003.

HAGE, J.J. et. al. Population dynamics of bovine herpes 1 infection in a dairy herd. Veterinary Microbiology, v.53, p.317-343, 1996.

LAGE, A.P. et al. Prevalence of antibodies to bluetongue, bovine herpesvirus 1 and bovine viral diarrhea/mucosal disease viruses in water buffaloes in Minas Gerais State, Brazil. Revue d'Elevage et de Médecine Vétérinaire des Pays Tropicaux, v.49, n.3, p.195-197, 1996.

JONES, C. Herpes simplex virus type 1 and bovine herpesvírus 1 latency. Clinical Microbiology Review, v.16, n.1, p.7995, 2003.

LOVATO, L.T. et al. Herpesvírus bovino tipo1 (BHV1): inquérito soro-epidemiológico no rebanho leiteiro do Estado do Rio Grande do Sul, Brasil. Ciência Rural, Santa Maria, v.25, n.3, p.425-430, 1995.

MÉDICE, K.C. et al. Prevalência de anticorpos neutralizantes

Ciência Rural, v.35, n.6, nov-dez, 2005. 
contra o herpesvírus bovino tipo 1, decorrentes de infecção natural, em rebanhos com distúrbios reprodutivos. Ciência Rural, Santa Maria, v.30, n.3, p.347-350, 2000.

MELO, C.B. et al. Prevalência de anticorpos contra Herpesvírus bovino-1, vírus da diarréia viral bovina e vírus da leucose enzoótica bovina em bovinos do Estado de Sergipe, Brasil. Revista Brasileira de Reprodução Animal, v.21, n.2, p.160-161, 1997.

MELO, C.B. et al. Distribuição de anticorpos para herpesvírus bovino 1 em rebanhos bovinos. Arquivo Brasileiro de Medicina Veterinária e Zootecnia, v.54, n.6, p.575-580, 2002.

METTENLEITER, T.C. Conclusions from the symposium. Veterinary Microbiology, v.53, p.207-211, 1996

OFFICE INTERNATIONAL DES EPIZOOTIES (OIE) 2002. International Animal Health Code. Manual of standards. Disponível em: http://oie.int/norms/mmanual. On line. Acesso em: 21 mar. 2002.

PITUCO, E.M. et al. Modelo alternativo para erradicação da Rinotraqueíte Infecciosa Bovina/ Vulvovaginite Infecciosa (IBR/ IPV) em rebanhos bovinos leiteiros. Arquivos do Instituto Biológico de São Paulo, v. 64, n.17, p.29, 1997.

RICHTZENHAIN, L.J. et al. Rinotraqueíte infecciosa bovina: levantamento sorológico nos Estados de Minas Gerais, Mato Grosso do Sul, São Paulo, Rio de Janeiro, Paraná e Rio Grande do Sul. Arquivos do Instituto Biológico de São Paulo, v.66, p.83-88, 1999.

ROCHA, W.V. Soroprevalência, distribuição regional e fatores de risco da brucelose em fêmeas bovinas adultas no Estado de Goiás. 2003. 63f. Dissertação (Mestrado em Sanidade Animal) - Curso de Pós-graduação em Medicina Veterinária, Escola de Veterinária, Universidade Federal de Goiás.

SILVA, F.F. et al. Anticorpos neutralizantes contra HVB 1 em bovinos do Estado de Pernambuco. Arquivo Brasileiro de
Medicina Veterinária e Zootecnia, v.47, n.4, p.597-599, 1995.

STRAUB, O.C. Advances in BHV1 (IBR) Research. Deutsche Tierärzliche Wochenschrift, v.108, p.419-422, 2001.

TONIN, F.B. et al. Prevalence of IBR and BVD/MD in bovine by EIE test. Virus Reviews \& Research, v.1, p.23, 1996. (abstract).

THRUSFIELD, M. Veterinary epidemiology. 2.ed. Oxford: Blackwell Science, 1999. 483p.

VAN SCHAIK, G. et al. Risk factors existence of bovine herpesvirus 1 antibodies on nonvaccinating Dutch dairy farms. Preventive Veterinary Medicine, v.34, n.3, p.125-136, 1998.

VAN SCHAIK, G. et al. Risk factors for introduction of BHV1 into BHV1-free farm Dutch dairy farms: a case-control study. Veterinary Quartelly, v.23, n.2, p.71-76, 2001.

VAN SCHAIK, G. et al. Probability of and risk factors for introduction of infectious diseases into Dutch SPF dairy farms: a cohort study. Preventive Veterinary Medicine, v.54, n.3, p.279-289, 2002.

VAN WUIJCKHUISE, J. et al. Epidemiological characteristics of bovine herpesvirus 1 infections determined by bulk milk testing of all Dutch dairy herds. Veterinary Record, v.142, p.181-184, 1998

VIDOR, T. et al. Herpes Bovino Tipo 1 (BHV-1): I. Sorologia de rebanhos com problemas reprodutivos. Ciência Rural, Santa Maria, v.25, n.3, p.421-424, 1995.

VIEIRA, S. et al. Anticorpos para o herpesvírus bovino 1(BHV1) em bovinos do Estado de Goiás. Ciência Animal Brasileira, v.4, n.2, p.131-137, 2003.

WENTINK, G.H. et al. Risk of infection with bovine herpes virus 1 (BHV1): a review. Veterinary Quartelly, v.15, n.1, p.30-33, 1993. 